\title{
How many times per day should peak expiratory flow rates be assessed when investigating occupational asthma?
}

Jean-Luc Malo, Johanne Côté, André Cartier, Louis-Philippe Boulet, Jocelyne L'Archevêque, Moira Chan-Yeung

\begin{abstract}
Background-Serial peak expiratory flow rate (PEF) recording has been advocated as a sensitive and specific means of confirming work related asthma. The optimum number of recordings per day to achieve the best between-reader and within-reader reproducibility and sensitivity/specificity ratio compared with the final diagnosis determined by specific inhalation challenges is unknown. Methods-PEF recording was carried out every two hours in 74 subjects referred for possible occupational asthma. Specific inhalation challenges performed in a hospital laboratory or at the workplace (positive in 33 subjects and negative in 41) were considered the gold standard. The duration of monitoring at work and away from work was at least two weeks each. Graphs of PEF recordings were generated in four different ways: every two hours, four times/day, three times/day, and every morning and evening. The graphs were assessed by three readers in three different centres in a blind manner. Furthermore, one third of each type of graph was read blind by the same reader one week after the initial interpretation.
\end{abstract}

Results-Agreement between the three readers was a little more frequent (82\%) in the case of the every two hour readings than for the other types of readings $\mathbf{( 7 0 \%}$ $v 77 \%$ ). Agreement between at least two of the three readers occurred in $73 \%$ of positive challenges (sensitivity) and in $78 \%$ of negative challenges (specificity) for every two hour readings. The figures varied from $61 \%$ to $70 \%$ for positive challenges and from $78 \%$ to $88 \%$ for negative challenges for the other types of readings. Within-subject reproducibility from one reading to the next (one week apart) was excellent ( $83 \%$ to $100 \%)$.

Conclusions-Recording PEF every two hours results in a slightly more satisfactory agreement between readers and in concordance in terms of sensitivityl specificity than less frequent PEF readings, although the four times a day assessment is almost as satisfactory.

(Thorax 1993;48:1211-1217)
Serial peak expiratory flow rate (PEF) monitoring has been advocated for assessing the severity of asthma ${ }^{12}$ and has been put forward in international guidelines aimed at reducing morbidity and mortality resulting from asthma. ${ }^{3-5}$ Burge and colleagues were the first to propose serial monitoring of PEF in the diagnosis of occupational asthma and they described several patterns of changes in PEF (hourly, daily, weekly). ${ }^{67}$ Serial assessment of PEF, sometimes coupled with monitoring of bronchial responsiveness, for periods at work and away from work has proved to be useful in the assessment of occupational asthma on an individual basis. ${ }^{89}$ Some surveys of high risk industries have also been carried out using this method of monitoring. ${ }^{10-13}$ This method of establishing a relation with the workplace in occupational asthma is simpler than specific inhalation challenges in the laboratory, and has the advantage of being feasible in centres where specific inhalation challenges are not available. The sensitivity of PEF monitoring in the diagnosis of occupational asthma compared with the results of specific inhalation challenge varied from $86 \%{ }^{14}$ to $81 \%,{ }^{15}$ while specificity varied from $89 \%{ }^{14}$ to $74 \% .^{15}$

Several methodological aspects of PEF monitoring are still unknown. Firstly, the ideal frequency of assessments is debatable; in previous studies monitoring was performed at least every two hours. It is unknown whether recording PEF less frequently would alter the sensitivity and specificity of the testing. Secondly, the degree of between-reader agreement is variable; Venables and colleagues reported that agreement between four observers occurred in $69 \%$ of 61 graphs $^{16}$ while Perrin and coworkers showed agreement between three readers in $89 \%$ of 61 graphs. ${ }^{15}$ However, these data should be interpreted with caution as the readers worked in the same centre; although the reading was blind, there could be an interpretation bias as the readers knew each other. The third unknown is the degree of within-reader agreement: the agreement was $90 \%$ to $100 \%$ in the study by Venables in which 29 graphs were recirculated and reread ${ }^{16}$ but, to the best of our knowledge, no other reports are available in the literature.

The purpose of our study was twofold: (1) to compare the results of PEF readings with 
the results of specific inhalation challenges using various ways of generating PEF graphs: every two hours, four times daily, three times daily, and morning and evening; (2) to evaluate the within-reader and between-reader reproducibility by having the graphs read by three readers working in three different centres, each with expertise in occupational asthma.

\section{Methods}

SUBJECTS

The graphs of 74 subjects investigated for occupational asthma who had undergone specific inhalation challenges were kept for analysis. The graphs satisfied the following criteria: at least two weeks at work (10 working days) were monitored (except in two subjects in whom PEF fell by more than $50 \%$ after two days at work and they had to stop working) and two weeks away from work.
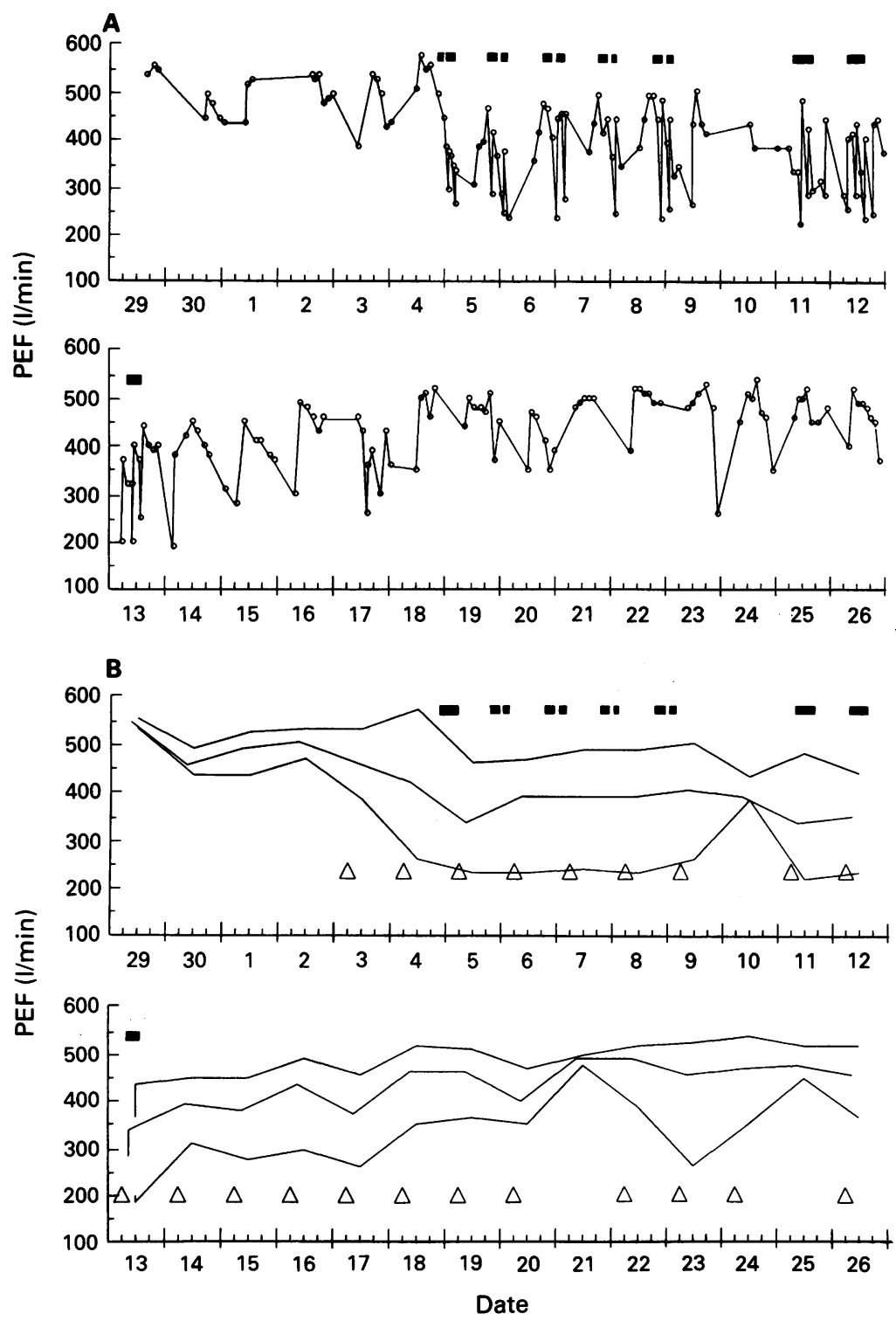

Figure 1 Graphs of the same subject with occupational asthma plotted using $(A)$ individual data and (B) daily mean, highest and lowest values. In the latter instance, triangles indicate days in which differences between the highest and lowest values were $20 \%$ or more. Periods at work are represented by the horizontal bars.
Table 1 Baseline anthropometric, clinical, and functional results of the 74 subjects

$\operatorname{Sex}(M / F)$

$68 / 6(92 \% / 8 \%)$

Smoking habits

(smokers, ex-smokers,

non-smokers)

$10 / 31 / 33(14 \% / 42 \% / 44 \%)$

Mean (SD) duration of exposure (years) $9 \cdot 4(8 \cdot 1)$

Mean (SD) duration of symptoms after onset of exposure (years)

Medication

Bronchodilators only $\quad 42(57 \%)$

Inhaled steroids $\quad 32(43 \%)$

Mean (SD) $\mathrm{FEV}_{1}$

(\% predicted)

$91(18)$

$\mathrm{PC}_{20}(\mathrm{mg} / \mathrm{ml})$

$12(16 \%)$

number $<0.25 \mathrm{mg} / \mathrm{ml}$

number $0.25-2 \mathrm{mg} / \mathrm{m}$

number $2-16 \mathrm{mg} / \mathrm{ml}$

$2(3 \%)$

$18(27 \%)$

number $>16 \mathrm{mg} / \mathrm{ml}$

$28(43 \%)$

$18(27 \%)$

Agents responsible Isocyanates

Western red cedar $\quad 18(24 \%)$

Sawmills

Flour and grains

$18(24 \%)$

5(7\%)

Formaldehyde $\quad 3(4 \%)$

Fluxes $3(4 \%)$

Amines

$3(4 \%)$
$2(3 \%)$

$13(17 \%)$

Others

The graphs had previously been included in two reports which assessed the sensitivity and specificity of PEF readings in the diagnosis of occupational asthma. ${ }^{14}{ }^{15}$ Subjects were asked to record their values approximately every two hours from first thing in the morning until going to bed in the evening. PEF readings from 74 of a total of 85 subjects who satisfied the above criteria were used. The mean (SD) duration of recording was $23(20)$ days for periods at work and 37 (22) days for periods away from work. The duration of monitoring at work was between 10 and 20 days in 43 subjects, between 20 and 40 days in 17 cases, and 40 days or more in 12 others. Duration of monitoring away from work was from 10 to 20 days in 18 subjects, from 20 to 40 days in 33 subjects, and for 40 days or more in 23 others. The characteristics of the subjects included in the study are shown in table 1.

\section{STUDY DESIGN}

Graphs were drawn in two different ways: (1) individual values of PEF taken before the use of inhaled $\beta_{2}$ adrenergic agents, and (2) plots of the highest, lowest, and mean daily values which assess the within-day variability, as suggested by Burge and coworkers ${ }^{67}$ (fig 1). Readers were given tracings drawn both ways and did not know whether one or another of the tracings was judged preferable or yielded the best sensitivity/specificity results. Graphs of PEF recordings were generated in four different ways: every two hours, four times/day, three times/day, and every morning and evening, and were numbered in a different sequence for each set. Values of the twice a 
Table 2 Concordance of readings for the three readers, without reference to the final diagnosis (gold standard = specific inhalation challenges), according to the four different types of graphs in 74 subjects

\begin{tabular}{llll}
\hline & $\begin{array}{l}\text { Graphs } \\
\text { interpreted } \\
\text { as positive }\end{array}$ & $\begin{array}{l}\text { Graphs } \\
\text { interpreted } \\
\text { as negative }\end{array}$ & $\begin{array}{l}\text { Total } \\
\text { number (\%) } \\
\text { agreement }\end{array}$ \\
\hline Agreement of 3/3 readers & & & \\
Every two hour readings & 24 & 37 & $61(82 \%)$ \\
Four times a day readings & 22 & 35 & $57(77 \%)$ \\
Three times a day readings & 16 & 36 & $52(70 \%)$ \\
Morning and evening readings & 20 & 37 & $57(77 \%)$ \\
Agreement of 2/3 readers & & & $13(18 \%)$ \\
Every two hour readings & 9 & 4 & $17(23 \%)$ \\
Four times a day readings & 10 & 7 & $22(30 \%)$ \\
Three times a day readings & 9 & 13 & $17(23 \%)$ \\
Morning and evening readings & 9 & 8 & \\
\hline
\end{tabular}

Agreement of all readers (top part) or of two thirds of readers (bottom part)

Table 3 Agreement of at least 2/3 or 3/3 readers according to results of specific inhalation challenges

\begin{tabular}{|c|c|c|}
\hline & $\begin{array}{l}\text { Positive specific } \\
\text { inhalation challenges } \\
(n=33)\end{array}$ & $\begin{array}{l}\text { Negative specific } \\
\text { inhalation challenges } \\
(n=41)\end{array}$ \\
\hline \multicolumn{3}{|l|}{ Agreement of $3 / 3$ readers: } \\
\hline Every two hour readings & $18(54 \%)$ & $29(71 \%)$ \\
\hline Four times a day readings & $16(49 \%)$ & $28(68 \%)$ \\
\hline Three times a day readings & $15(46 \%)$ & $27(66 \%)$ \\
\hline Morning and evening readings & $17(49 \%)$ & $29(71 \%)$ \\
\hline \multicolumn{3}{|l|}{ Agreement of $2 / 3$ readers: } \\
\hline Every two hour readings & $6(18 \%)$ & $3(7 \%)$ \\
\hline Four times a day readings & $7(21 \%)$ & $4(10 \%)$ \\
\hline Three times a day readings & $5(15 \%)$ & $9(22 \%)$ \\
\hline Morning and evening readings & $4(12 \%)$ & $4(10 \%)$ \\
\hline \multicolumn{3}{|c|}{ Agreement of at least $2 / 3$ readers (total): } \\
\hline Every two hour readings & $24(72 \%)$ & $32(78 \%)$ \\
\hline Four times a day readings & $23(70 \%)$ & $32(72 \%)$ \\
\hline Three times a day readings & $20(61 \%)$ & $36(88 \%)$ \\
\hline Morning and evening readings & $21(64 \%)$ & $33(80 \%)$ \\
\hline
\end{tabular}

day tracings were the values requested on waking up in the morning and before going to bed in the evening. Those of the three times a day tracings also included values obtained at noon ( \pm one hour), and those of the four times a day tracings had, in addition, a value obtained around supper time. Tracings were assessed by three readers in three different centres (JLM, JC, and MCY) in a blind manner-that is, without knowledge of the other readers' results or of the specific inhalation

Table 4 Distinction between subjects on bronchodilators (BDT) only and those on inhaled steroids

\begin{tabular}{|c|c|c|c|c|}
\hline & \multicolumn{2}{|c|}{$\begin{array}{l}\text { Positive specific } \\
\text { inhalation challenges } \\
(n=33)\end{array}$} & \multicolumn{2}{|c|}{$\begin{array}{l}\text { Negative specific } \\
\text { inhalation challenges } \\
(n=41)\end{array}$} \\
\hline & $\begin{array}{l}\text { BDT } \\
\text { only } \\
(n=18)\end{array}$ & $\begin{array}{l}\text { Inhaled } \\
\text { steroids } \\
(n=15)\end{array}$ & $\begin{array}{l}B D T \\
\text { only } \\
(n=24)\end{array}$ & $\begin{array}{l}\text { Inhaled } \\
\text { steroids } \\
(n=17)\end{array}$ \\
\hline \multicolumn{5}{|l|}{ Agreement of $3 / 3$ readers: } \\
\hline Every two hour readings & $11(61 \%)$ & $7(47 \%)$ & $17(71 \%)$ & $12(71 \%)$ \\
\hline Four times a day readings & $7(39 \%)$ & $9(60 \%)$ & $16(67 \%)$ & $12(71 \%)$ \\
\hline Three times a day readings & $7(39 \%)$ & $8(53 \%)$ & $14(58 \%)$ & $13(76 \%)$ \\
\hline Morning and evening readings & $9(50 \%)$ & $8(53 \%)$ & $16(67 \%)$ & $13(76 \%)$ \\
\hline \multicolumn{5}{|l|}{ Agreement of $2 / 3$ readers: } \\
\hline Every two hour readings & $2(11 \%)$ & $4(27 \%)$ & $1(4 \%)$ & $2(12 \%)$ \\
\hline Four times a day readings & $6(33 \%)$ & $1(7 \%)$ & $1(4 \%)$ & $3(18 \%)$ \\
\hline Three times a day readings & $4(22 \%)$ & $1(7 \%)$ & $6(25 \%)$ & $3(18 \%)$ \\
\hline Morning and evening readings & $3(17 \%)$ & $1(7 \%)$ & $3(13 \%)$ & $1(6 \%)$ \\
\hline
\end{tabular}

challenge results. Furthermore, one third of each type of graph was read blind by the same reader one week after the initial interpretation. Readers were asked to classify each graph as either suggestive or non-suggestive of occupational asthma.

Spirometric measurements were assessed according to proposed standards. ${ }^{17}$ Bronchial responsiveness to histamine or methacholine was assessed with a Bennett twin nebuliser (output $0.25 \mathrm{ml} / \mathrm{min}$ ) in the case of subjects exposed to Western red cedar, ${ }^{18}$ and with a Wright nebuliser (output $0.13 \mathrm{ml} / \mathrm{min}$ ) for the other subjects. ${ }^{19} \mathrm{~A} \quad \mathrm{PC}_{20}$ result $\leqslant 16$ $\mathrm{mg} / \mathrm{ml}$ was considered suggestive of increased bronchial responsiveness. ${ }^{20}$ The lowest value of $\mathrm{PC}_{20}$ at any time was given to the readers with the graphs of PEF (except in eight cases for which these results were not available). Specific inhalation challenges were carried out by nebulising the active agent, plicatic acid, in the case of subjects sensitive to Western red cedar, ${ }^{21}$ in hospital challenge rooms $^{22-24}(n=60)$ or at work by monitoring spirometric values over an eight hour workplace challenge test and comparing it with a period of no exposure in the hospital laboratory $(n=14)$. Subjects with occupational asthma due to Western red cedar were investigated in Vancouver and the others in Montreal or Quebec City.

\section{ANALYSIS OF RESULTS}

Concordance tables were used for comparing results of PEF recordings with the results of specific inhalation challenges and the results of workplace challenge tests. The $t$ test for proportion was used in analysing results presented in the concordance tables.

\section{Results}

As shown in table 1, most subjects were men and non-smokers or ex-smokers. The majority were on bronchodilators only at the time of assessment and had a normal $\mathrm{FEV}_{1} ; 40$ of $66(61 \%)$ showed increased bronchial responsiveness. Isocyanates and Western red cedar were the most common occupational agents.

The concordance of between-reader interpretations is shown in table 2. Although there was no statistical difference, there was slightly better concordance in terms of the sensitivity/specificity ratio among the three readers for the every two hour graphs than for the other types of patterns.

The best sensitivity/specificity ratio with the agreement of at least two of the three readers was also obtained by examining the every two hour graphs ( $72 \%$ sensitivity, $78 \%$ specificity), but the four times a day readings were almost as accurate $(70 \%$ sensitivity, $78 \%$ specificity) (table 3). However, again no statistical differences were obtained by comparing these percentages. Ratios were less satisfactory for the three times a day and morning and evening readings. Distinguishing between subjects on inhaled steroids and those who took bronchodilators only did not modify the sensitivity/specificity 

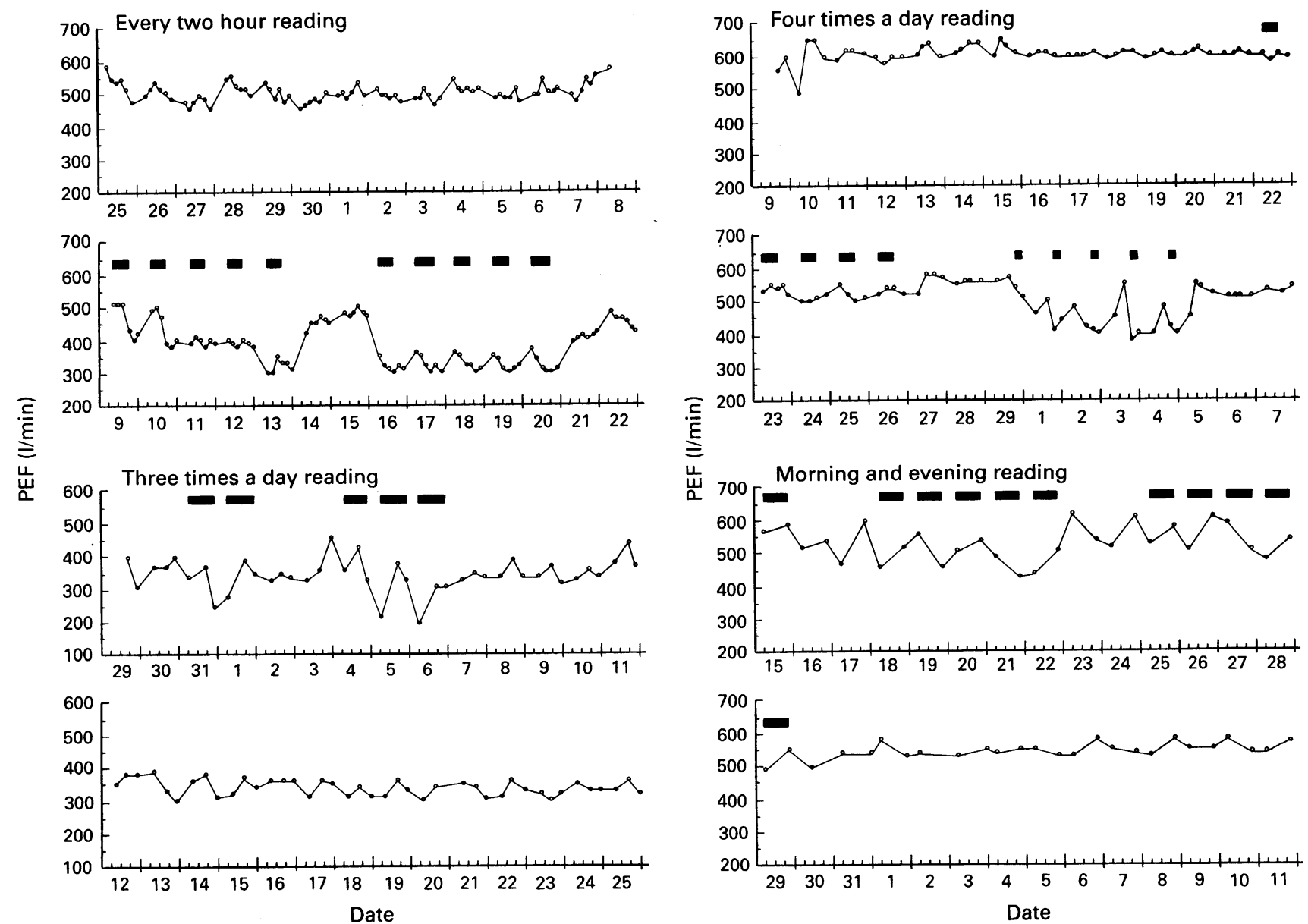

Figure 2 Graphs (four different patterns) where there was agreement among the three readers for four different subjects with occupational asthma as proven by specific inhalation challenges. Periods at work are represented by the horizontal bars.

ratios (table 4). Figures 2 and 3 show examples for the four graph patterns where agreement of the three readers was obtained in the presence or absence of occupational asthma according to the results of specific inhalation challenges. Figure 4 shows examples of where the three readers interpreted the graphs as negative while specific inhalation challenges were positive.

The within-reader reproducibility for the 22-24 graphs (depending on the pattern) that

Table 5 Within-reader reproducibility of individual tracings over time (one week apart) for the three readers

\begin{tabular}{|c|c|c|c|}
\hline & $\begin{array}{l}\text { Positive on } \\
\text { both occasions }\end{array}$ & $\begin{array}{l}\text { Negative on } \\
\text { both occasions }\end{array}$ & Total \\
\hline \multicolumn{4}{|l|}{ Reader no. 1: } \\
\hline Every two hour readings & 13 & 9 & $22 / 23(96 \%)$ \\
\hline Four times a day readings & 11 & 11 & $22 / 24(92 \%)$ \\
\hline Three times a day readings & 6 & 16 & $22 / 23(96 \%)$ \\
\hline Morning and evening readings & 9 & 12 & $21 / 22(96 \%)$ \\
\hline \multicolumn{4}{|l|}{ Reader no. 2: } \\
\hline Every two hour readings & 13 & 9 & $22 / 23(96 \%)$ \\
\hline Four times a day readings & 12 & 9 & $21 / 24(88 \%)$ \\
\hline Three times a day readings & 11 & 12 & $23 / 22(100 \%)$ \\
\hline Morning and evening readings & 11 & 10 & $21 / 22(96 \%)$ \\
\hline \multicolumn{4}{|l|}{ Reader no. 3: } \\
\hline Every two hour readings & 10 & 13 & $23 / 23(100 \%)$ \\
\hline Four times a day readings & 9 & 11 & $20 / 24(83 \%)$ \\
\hline Three times a day readings & 6 & 16 & $22 / 23(96 \%)$ \\
\hline Morning and evening readings & 6 & 13 & $19 / 22(86 \%)$ \\
\hline
\end{tabular}

were read one week apart in a blind manner was excellent, the concordance varying from $83 \%$ to $100 \%$ depending on the readers and the types of graphs (table 5).

\section{Discussion}

This study shows that the visual method of interpreting the graphs of PEF recorded every two hours has two advantages over less frequent recordings. The first is a greater agreement $(82 \%)$ between three readers, and the $\frac{D}{0}$ second is a greater concordance in terms of sensitivity and specificity ratios compared $N$ with the results of specific inhalation challenges. These differences were not statistically significant, however, and were slight, particularly when compared with the four times a day recording; in that instance the agreement between the three readers reached $77 \%$ and $\stackrel{0}{?}$ figures for sensitivity and specificity were 0 $70 \%$ and $78 \%$, respectively. It is also obvious that this judgement is based on a balance of sensitivity/specificity values. In some $\stackrel{\mathbb{D}}{\AA}$ instances it might be preferable to have higher sensitivity results even if specificity is lower or vice versa.

We had no direct means of assessing the subjects' compliance nor the reliability of the PEF recording. It is possible that asking subjects to record their PEF every two hours may result in lower compliance and less reliable 

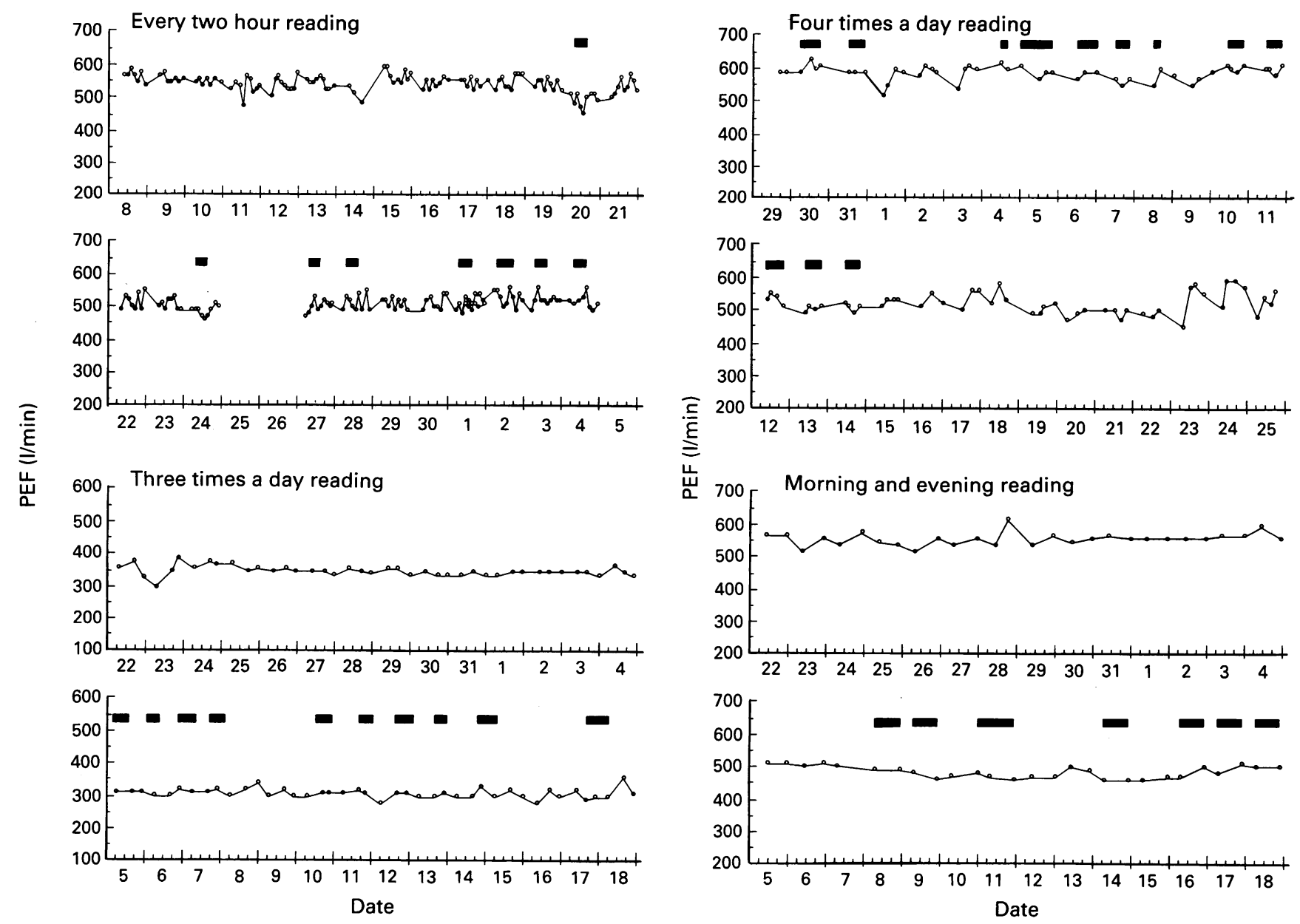

Figure 3 Graphs (four different patterns) where there was agreement among the three readers for four different subjects without occupational asthma as shown by specific inhalation challenges. Periods at work are represented by the horizontal bars.

readings. Subjects may invent data if they forget to take the measurement. At the time this study was carried out, only instruments that recorded PEF were available. However, now PEF can be measured and the data stored on a computer chip. These new instruments can provide a means of assessing compliance and the accuracy of the data recorded.

Our study also shows that sensitivity/specificity ratios for the concordance of PEF readings to the results of specific inhalation challenges were not affected by the use of medication (bronchodilators only as opposed to inhaled anti-inflammatory preparations). This differs from the conclusion reached by Burge and coworkers ${ }^{7}$ who found that sensitivity was $42 \%$ for subjects taking anti-inflammatory preparations and $77 \%$ for subjects not taking them. In their report the "gold standard" was not the result of specific inhalation challenges but the final diagnostic impression of the physician. ${ }^{7}$

Lower sensitivity and specificity of PEF readings compared with the results of specific inhalation challenges in this study, which included 74 of 85 subjects (87\%) who took part in two previously published studies, ${ }^{1415}$ can be due to the fact that the graphs in this study were interpreted by three readers working in three different centres, whereas in previous studies graphs were interpreted by three readers from the same centre. Having inter- preters working in the same centre may introduce a contamination bias. We do not think that these results can be due to a preselection of graphs which were either "easy" or "difficult" to interpret. The 85 original subjects were not selected and entered the study prospectively. Subjects who were excluded in the current report $(n=11)$ did not satisfy preset criteria of two weeks of recording at work and away from work. As outlined in a previous report, this study included subjects who were not necessarily continuously exposed to the offending agent. ${ }^{15}$ This was the case, in particular, for subjects exposed to isocyanates and to some agents such as formaldehyde, fluxes or amines. In these subjects it may be more difficult to identify correctly the timing of exposure at work, which can be brief at times and insufficient for eliciting an asthmatic reaction. In other instances the exposure can be indirect and the worker unaware of exposure to the agent. Although this point cannot be verified, it is possible that difficulty in assessing true exposure intervals at work can account for the difficulty in assessing tracings.

The observers were only asked to make a categorical assessment of the peak flows-that is, either suggestive or non-suggestive of occupational asthma. We did not use an extended scale as in a previous report, ${ }^{16}$ the reasons being that we wanted to mimic the 

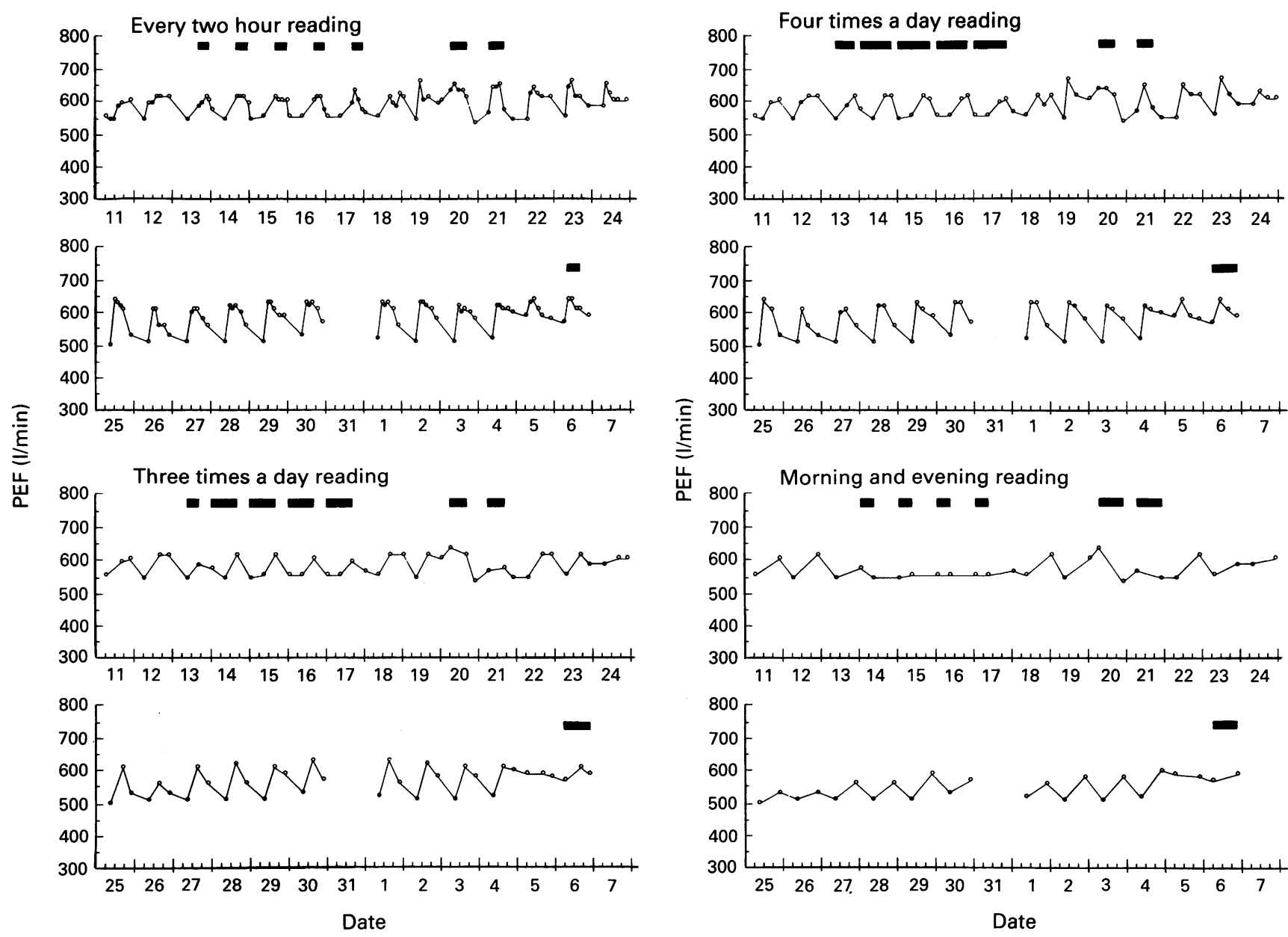

Figure 4 Graphs (four different patterns) where there was disagreement among the three readers for four different subjects with occupational asthma as proven by specific inhalation challenges. Periods at work are represented by the horizontal bars.

situation in which a physician has to make a decision on examining a tracing, and we would have needed more subjects to make results interpretable. This method of interpreting tracings can increase or decrease between-observer agreement, but this should not have influenced results of sensitivity and specificity.

Some recently developed instruments are capable of recording PEF and $\mathrm{FEV}_{1}$ during the same expiratory manoeuvre. It has been shown that $\mathrm{FEV}_{1}$ is more sensitive than PEF in identifying late asthmatic reactions after exposure to occupational agents in the laboratory. ${ }^{25}$ These instruments may therefore offer better means of assessing changes in airway calibre during periods at work.

Investigation of occupational asthma is a stepwise procedure. ${ }^{26} \mathrm{~A}$ questionnaire alone is not sufficiently sensitive nor specific to make a diagnosis of occupational asthma. ${ }^{27}$ Increased specific IgE or IgG antibody levels are markers of "sensitisation" and do not necessarily mean that the target organ is involved. ${ }^{12} 28$ Objective confirmation of a work-related alteration in airway calibre, or bronchial responsiveness, or both is therefore essential for medical and medicolegal purposes. Several retrospective studies have shown that being exposed and symptomatic for longer intervals results in the persistence of more severe asthma, lower spirometric values, and a higher degree of bronchial hyperresponsiveness..$^{29-31}$ Early diagnosis is therefore necessary since advising a patient to leave his/her workplace results in considerable $\operatorname{cost}^{32}$ and a reduction in quality of life. ${ }^{33}$

Although sensitivity and specificity figures and between-reader agreement are far from perfect, PEF monitoring is a valuable means 옥 of assessing occupational asthma since specific inhalation challenges are only available in specialised centres and, in some circum- No stances, specific inhalation challenges may be falsely negative. This is the case if subjects cease to be exposed for a long interval or if the wrong agent is used for the specific inhalation challenge. There is clearly a need for sending subjects back to work with serial PEF monitoring if specific inhalation challenges are negative in the laboratory, as was recently suggested. ${ }^{26}$

In conclusion, we found that assessing PEF every two hours resulted in a slightly higher between-reader reproducibility and a marginally better concordance with the 8 results of specific inhalation challenges. Nevertheless, these differences were slight $\frac{\overline{0}}{\partial}$ and assessment of PEF on a four times a day basis can be adequate. Less frequent assessments were not as satisfactory. 
The authors are members of the Canadian Government Respiratory Health Network of Centres of Excellence. JLM is a research fellow with the Fonds de la recherche en santé du Québec and of the Université de Montréal School of Medicine.

This work was done with the encouragement of the Scientific Committee of Respiratory Disease of the International Union Against Tuberculosis and Lung Diseases (IUATLD). The authors would like to express their gratitude to Katherine Tallman for reviewing the manuscript.

1 Turner-Warwick $M$. On observing patterns of airflow obstruction in chronic asthma. Br $\mathcal{F}$ Ind Med 1977; 71:73-86.

2 Hetzel M, Clark T, Branthwaite $M$. Asthma: analysis of sudden deaths and ventilatory arrests in hospital. $B M \mathcal{J}$ 1977;1:808-11.

3 Woolcock A, Rubinfeld A, Seale J, Landau LI, Antic R, Mitchell C, et al. Asthma management plan, 1989. Med f Aust 1989;151:650-3

4 Hargreave F, Dolovich J, Newhouse $M$. The assessment and treatment of asthma: a conference report. F Allergy Clin Immunol 1990;85:1098-111.

5 National Heart, Lung, and Blood Institute, National Institutes of Health, Bethesda, Maryland 20892. International consensus report on diagnosis and treatment of asthma. Eur Respir $\mathcal{f} 1992 ; 5: 601-41$.

6 Burge P, O'Brien I, Harries M. Peak flow rate records in the diagnosis of occupational asthma due to isocyanates. Thorax 1979;34:317-23.

7 Burge P, O'Brien I, Harries M. Peak flow rate records in the diagnosis of occupational asthma due to colophony. Thorax 1979;34:308-16.

8 Cockcroft D, Cartier A, Jones G, Tarlo S, Dolovich J, Hargreave F. Asthma caused by occupational exposure to a furan-based binder system. I Allergy Clin Immunol $1980 ; 66: 458-63$

9 Cartier A, Pineau L, Malo JL. Monitoring of maximum expiratory peak flow rates and histamine inhalation tests in the investigation of occupational asthma. Clin Allergy 1984;14:193-6.

10 Cartier A, Malo JL, Forest F, Lafrance M, Pineau L, St-Aubin J, et al. Occupational asthma in snow crabprocessing workers. F Allergy Clin Immunol 1984;74: 261-9.

11 Malo JL, Cartier A. Occupational asthma in workers of a pharmaceutical company processing spiramycin. Thorax 1988;43:371-7.

12 Bardy J, Malo J, Séguin $P$, Ghezzo $H$, Desjardins J, Dolovich J, et al. Occupational asthma and IgE sensitization in a pharmaceutical company processing psyllium. Am Rev Respir Dis 1987;135:1033-8.

13 Smith AB, Bernstein D, London M, Gallagher J, Ornella GA, Gelletly SK, et al. Evaluation of occupational asthma from airborne egg protein exposure in multiple settings. Chest 1990;98:398-404.

14 Côté J, Kennedy S, Chan-Yeung M. Sensitivity and specificity of $\mathrm{PC}_{20}$ and peak expiratory flow rate in cedar asthma. F Allergy Clin Immunol 1990;85:592-8.

15 Perrin B, Lagier F, L'Archevêque J, Cartier A, Boulet LP, Côté $\mathrm{J}$, et al. Occupational asthma: validity of monitoring of peak expiratory flow rates and non-allergic bronchial responsiveness as compared to specific inhala- tion challenge. Eur Respir ₹ 1992;5:40-8.

16 Venables K, Burge PS, Davison A, Taylor AN. Peak flow rate records in surveys: reproducibility of observers' reports. Thorax 1984;39:828-32.

17 American Thoracic Society. Standardization of spirometry: 1987 update. $A m$ Rev Respir Dis 1987;136: 1285-307.

18 Lam S, Wong $R$, Chan-Yeung $M$. Nonspecific bronchial reactivity in occupational asthma. F Allergy Clin Immunol 1979;63:28-34.

19 Cockcroft D, Killian D, Mellon J, Hargreave F. Bronchial reactivity to inhaled histamine: a method and clinical survey. Clin Allergy 1977;7:235-43.

20 Malo JL, Pineau L, Cartier A, Martin R. Reference values of the provocative concentrations of methacholine that cause $6 \%$ and $20 \%$ changes in forced expiratory volume in one second in a normal population. Am Rev Respir Dis 1983;128:8-11.

21 Chan-Yeung M, Barton G, MacLean L, Grzybowski S. Occupational asthma and rhinitis due to Western red cedar (Thuja plicata). Am Rev Respir Dis 1973;108: 1094-102.

22 Pepys J, Hutchcroft B. Bronchial provocation tests in etiologic diagnosis and analysis of asthma. Am Rev Respir Dis 1975;112:829-59.

23 Cloutier Y, Lagier F, Lemieux R, Blais MC, St-Arnaud C, Cartier A, et al. New methodology for specific inhalation challenges with occupational agents in powder form. Eur Respir F 1989;2:769-77.

24 Vandenplas O, Malo J, Cartier A, Perreault G, Cloutier Y. Closed-circuit methodology for inhalation challenge tests with isocyanates. Am Rev Respir Dis 1991;145: 582-7.

25 Bérubé D, Cartier A, L'Archevêque J, Ghezzo H, Malo $\mathrm{JL}$. Comparison of peak expiratory flow rate and FEV in assessing bronchomotor tone after challenges with occupational sensitizers. Chest 1991;99:831-6.

$26 \mathrm{Malo} \mathrm{JL}$. Application of provocative challenge studies in the diagnosis of occupational asthma. Immunol Allergy Clin North Am 1992;12:879-96.

27 Malo JL, Ghezzzo H, L'Archevêque J, Lagier F, Perrin B Cartier $A$. Is the clinical history a satisfactory means of diagnosing occupational asthma? Am Rev Respir Dis 1991;143:528-32.

28 Cartier A, Grammer L, Malo JL, Lagier F, Ghezzo H, Harris $\mathrm{K}$, et al. Specific serum antibodies against isocyanates: association with occupational asthma. f Allergy Clin Immunol 1989;84:507-14.

29 Chan-Yeung $M$, Lam S, Koener S. Clinical features and natural history of occupational asthma due to Western red cedar (Thuja plicata). Am $\mathcal{F}$ Med 1982;72:411-5.

30 Hudson P, Cartier A, Pineau L, Lafrance M, St-Aubin JJ, Dubois JY, et al. Follow-up of occupational asthma caused by crab and various agents. $\mathcal{f}$ Allergy Clin caused by crab and vari

31 Mapp C, Corona P, De Marzo N, Fabbri L. Persistent asthma due to isocyanates. A follow-up study of subjects with occupational asthma due to toluene diisocyanate. Am Rev Respir Dis 1988;137:1326-9.

32 Malo JL, Boulet LP, Dewitte JD, Cartier A, L'Archevêque J, Côté J, et al. Quality of life of subjects with occupational asthma. I Allergy Clin Immunol 1993;91:1121-7.

33 Malo JL, Dewitte JD, Cartier A, Ghezzo H, L'Archevêque $\mathrm{J}$, Boulet LP, et al. The Quebec system of compensation for occupational asthma: description, effectiveness and cost. Rev Mal Respir 1993;10:313-23. 